Case Report

\title{
Effective Treatment of a Malignant Breast Phyllodes Tumor with Doxorubicin-Ifosfamide Therapy
}

\author{
Shinya Yamamoto ${ }^{D},{ }^{1}$ Shigeru Yamagishi, ${ }^{1}$ Toshiro Kohno, ${ }^{2}$ Ryosuke Tajiri, ${ }^{3}$ \\ Toshikazu Gondo, ${ }^{3}$ Noboru Yoshimoto, ${ }^{4}$ and Nobuko Kusano ${ }^{5}$ \\ ${ }^{1}$ Department of Breast Surgery, Fujisawa City Hospital, 2-6-1 Fujisawa, Fujisawa City, Kanagawa 251-8550, Japan \\ ${ }^{2}$ Shonan Fujisawa Clinic, 1-15 Hanazawa-cho, Kugenuma, Fujisawa City, Kanagawa 251-0023, Japan \\ ${ }^{3}$ Department of Diagnostic Pathology, Fujisawa City Hospital, 2-6-1 Fujisawa, Fujisawa City, Kanagawa 251-8550, Japan \\ ${ }^{4}$ Department of Thoracic Surgery, Fujisawa City Hospital, 2-6-1 Fujisawa, Fujisawa City, Kanagawa 251-8550, Japan \\ ${ }^{5}$ Ambulatory Treatment Center, Fujisawa City Hospital, 2-6-1 Fujisawa, Fujisawa City, Kanagawa 251-8550, Japan \\ Correspondence should be addressed to Shinya Yamamoto; shinya@rf.catv.ne.jp
}

Received 11 February 2019; Revised 21 May 2019; Accepted 1 June 2019; Published 18 June 2019

Academic Editor: Katsuhiro Tanaka

Copyright (c) 2019 Shinya Yamamoto et al. This is an open access article distributed under the Creative Commons Attribution License, which permits unrestricted use, distribution, and reproduction in any medium, provided the original work is properly cited.

\begin{abstract}
Malignant phyllodes tumors of the breast occur infrequently and are difficult to treat with chemotherapy. Here, we present an effective chemotherapy strategy for recurrent malignant breast phyllodes tumors. A 48-year-old woman was diagnosed with a malignant phyllodes tumor in her right breast and underwent total right mastectomy. One year later, the tumor recurred in the right (a $2.2 \mathrm{~cm}$ mass) and left (a $10 \mathrm{~cm}$ mass) lungs; pleural effusion was also observed in the left lung. Eight courses of doxorubicin-ifosfamide (AI) therapy were administered. After treatment, the right lung mass and pleural effusion regressed completely and the left lung mass regressed to $2 \mathrm{~cm}$. In conclusion, AI therapy is useful for treating recurrent malignant breast phyllodes tumors.
\end{abstract}

\section{Introduction}

Malignant phyllodes tumors of the breast are infrequent, and effective chemotherapy strategies are lacking. Here, we describe an effective treatment strategy for recurrent malignant breast phyllodes tumors.

\section{Case Presentation}

A 48-year-old woman presented to our hospital with a mass in her right breast (Figure 1). A malignant phyllodes tumor was diagnosed via core needle biopsy, and right total mastectomy was performed. The pathological findings were consistent with the preoperative diagnosis, and the margins of the resected tissue were negative.

One year later, the patient presented with cough and dyspnea. Computed tomography revealed a $2.2 \mathrm{~cm}$ mass in the right lung (Figure 2(a)) and $10 \mathrm{~cm}$ mass and pleural effusion in the left lung (Figure 2(b)). The masses were diagnosed as recurrent malignant phyllodes tumors. They were deemed unresectable because they were present in both lungs, and pleural dissemination was suspected.

As an alternative treatment, we administered 8 courses of doxorubicin-ifosfamide (AI) therapy $\left(30 \mathrm{mg} / \mathrm{m}^{2}\right.$ doxorubicin on days 1-2 and $2 \mathrm{~g} / \mathrm{m}^{2}$ ifosfamide on days 1-5) (Table 1 ). After chemotherapy, the right lung mass regressed completely (Figure 3(a)), the left lung mass regressed to $2 \mathrm{~cm}$ (Figure 3(b)), and pleural effusion was no longer detected. All 8 courses of AI therapy included mesna (sodium 2-mercaptoethane sulfonate) and sufficient infusion volumes to prevent ifosfamide-related hemorrhagic cystitis. Hemorrhagic cystitis did not occur during any of the courses.

Grade 4 neutropenia (as defined by the Common Terminology Criteria for Adverse Events (CTCAE)) occurred on 


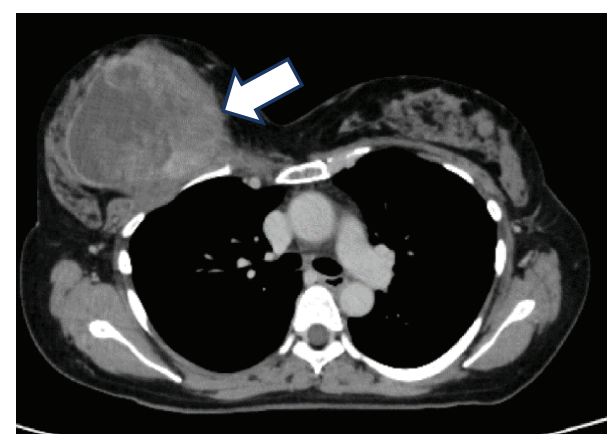

FIGURE 1: Computed tomography scan showing a 9-cm mass in the right breast (arrow).

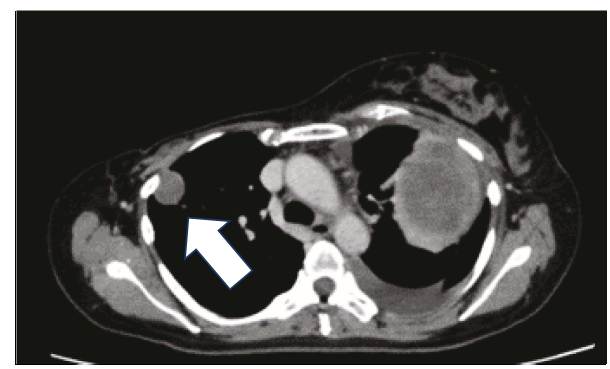

(a)

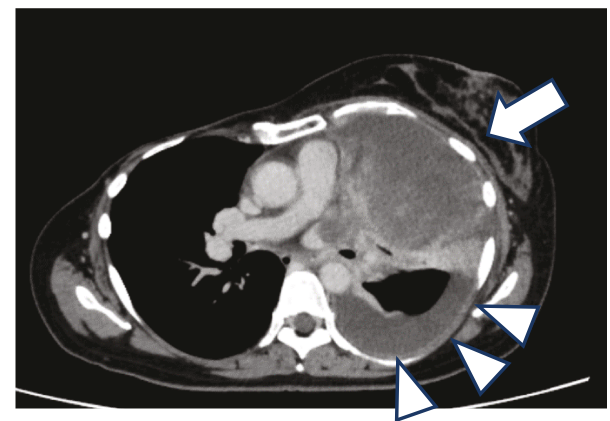

(b)

Figure 2: Computed tomography scan acquired before doxorubicin-ifosfamide (AI) chemotherapy showing (a) a $2.2 \mathrm{~cm}$ mass in the right lung (arrow) and (b) a $10 \mathrm{~cm}$ mass (arrow) and pleural effusion in the left lung (arrowheads).

day 15 of the first treatment cycle. To prevent the neutropenia from advancing, filgrastim, a granulocyte colonystimulating factor, was administered on days 15 and 16 of the first cycle and pegfilgrastim, a persistent granulocyte colony-stimulating factor, was administered on day 8 or 9 of the following cycle. Febrile neutropenia was not observed during any of the courses.

We administered a diuretic drug at a concentration appropriate for the patient's weight when indicated, as well as a selective neurokinin 1 (NK1) receptor antagonist or other antiemetic. NK1 receptor antagonist administration was extended to 5 days owing to grade 2 nausea (as defined by the CTCAE) after the second cycle, and good control of the nausea was achieved. No other severe adverse events were noted. To avoid cardiotoxicity, AI therapy was terminated after 8 courses. Surgery was considered at this point but was refused by the patient. Thus, 4 courses of docetaxel $\left(75 \mathrm{mg} / \mathrm{m}^{2}\right)$ were administered instead.

Although the right lung mass did not reappear (Figure 4(a)), the left lung mass increased in size to $5.5 \mathrm{~cm}$ (Figure 4(b)). As a result, the patient consented to surgery. Total left lung extraction and partial pericardial resection were performed. Pathological findings were consistent with a diagnosis of lung-metastatic breast phyllodes tumor, and curative resection was achieved (Figure 5). Four months after lung surgery, a $10 \mathrm{~cm}$ mass in the mediastinum (Figure 6(a)) and $6 \mathrm{~cm}$ mass in the left thoracic cavity (Figure 6(b)) were observed. The patient was therefore diagnosed with recurrent malignant phyllodes tumor of the left lung. One course of ifosfamide monotherapy $\left(2 \mathrm{~g} / \mathrm{m}^{2}\right.$ on days $\left.1-4\right)$ was administered. However, the patient's condition worsened abruptly before discharge and she died.

\section{Discussion}

Breast phyllodes tumors account for only $0.3 \%-0.9 \%$ of all breast tumors [1]. Based on their histological features, they are classified as benign, boundary, or malignant; $13 \%-40 \%$ of malignant tumors show metachronous distant metastases. Owing to the low frequency of distant metastasis, only a small number of retrospectively analyzed cases have been reported and a treatment strategy for malignant breast phyllodes tumors has not been established. Chemotherapy for unresectable distant metastases of malignant breast phyllodes tumors is generally similar to that used for soft tissue sarcomas [2]. The usefulness of anthracycline- and ifosfamidebased regimens $[3,4]$, as well as of high-capacity ifosfamide or anthracyclines plus granulocyte-macrophage colonystimulating factor, for treatment of soft tissue sarcomas has been reported [5-7]. In accordance with previous reports [3-7], we administered AI therapy, using $60 \mathrm{mg} / \mathrm{m}^{2}$ doxorubicin and $10 \mathrm{~g} / \mathrm{m}^{2}$ ifosfamide in each course. Because doxorubicin can be cardiotoxic, its total dose did not exceed $500 \mathrm{mg} / \mathrm{m}^{2}$. Regarding the dose indication of Adriamycin in our country, it is known that up to $500 \mathrm{mg}$ is safe to administer.

Leyvraz et al. administered a combination of high-dose ifosfamide and high-dose doxorubicin to patients with soft tissue sarcomas [8], although at different doses than those used in our study. A total of 187 chemotherapy cycles were administered, and salvage therapy was also performed. The adverse events observed (and the percentage of cycles in which they occurred) were as follows: grade 3 neutropenia (59\%), febrile episodes (29\%), grade 3 thrombocytopenia (39\%), anemia (27\%), and transient microscopic hematuria (9\%). One patient died of septic shock during the fourth cycle. There were no instances of severe renal toxicity.

In our study, the right lung mass completely regressed after 8 courses of AI therapy, and the left lung mass regressed considerably. Hence, AI therapy was very effective. After AI therapy, we considered surgery (which the patient refused) and ifosfamide single-agent therapy (which we ultimately rejected owing to slow tumor regression during the second half of AI therapy). Instead, we opted to administer docetaxel, the usefulness of which has been reported [9]. The 
TABLE 1: Doxorubicin-ifosfamide (AI) therapy regimen.

\begin{tabular}{|c|c|c|c|c|}
\hline & Drug & Volume/dose & Infusion time & Timing of administration \\
\hline \multicolumn{5}{|c|}{ Days 1-2 } \\
\hline \multirow{2}{*}{ Rp. 1} & Saline & $500 \mathrm{~mL}$ & & \\
\hline & SHC & $20 \mathrm{~mL}$ & $4 \mathrm{~h}$ & \\
\hline \multirow{3}{*}{ Rp. 2} & Saline & $100 \mathrm{~mL}$ & & \\
\hline & PH (day 1 only) & $0.75 \mathrm{mg}$ & & \\
\hline & Dexamethasone & $9.9 \mathrm{mg}$ & $15 \mathrm{~min}$ & \\
\hline \multirow{2}{*}{ Rp. 3} & Saline & $100 \mathrm{~mL}$ & & \\
\hline & Doxorubicin & $30 \mathrm{mg} / \mathrm{m}^{2}$ & $2 \mathrm{~h}$ & \\
\hline \multirow{2}{*}{ Rp. 4} & Saline & $50 \mathrm{~mL}$ & & \\
\hline & Mesna & $400 \mathrm{~mL} / \mathrm{m}^{2}$ & $15 \mathrm{~min}$ & \\
\hline \multirow{2}{*}{ Rp. 5} & Saline & $500 \mathrm{~mL}$ & & \\
\hline & Ifosfamide & $2 \mathrm{~g} / \mathrm{m}^{2}$ & $4 \mathrm{~h}$ & \\
\hline \multirow{2}{*}{ Rp. 6} & Saline & $500 \mathrm{~mL}$ & & \\
\hline & SHC & $20 \mathrm{~mL}$ & $4 \mathrm{~h}$ & \\
\hline \multirow{2}{*}{ Rp. 7} & Saline & $50 \mathrm{~mL}$ & & \\
\hline & Mesna & $400 \mathrm{~mL} / \mathrm{m}^{2}$ & $15 \mathrm{~min}$ & $4 \mathrm{~h}$ after Rp. 5 administration \\
\hline \multirow{2}{*}{ Rp. 8} & Saline & $500 \mathrm{~mL}$ & & \\
\hline & SHC & $20 \mathrm{~mL}$ & $4 \mathrm{~h}$ & \\
\hline \multirow{2}{*}{ Rp. 9} & Saline & $50 \mathrm{~mL}$ & & \\
\hline & Mesna & $400 \mathrm{~mL} / \mathrm{m}^{2}$ & $15 \mathrm{~min}$ & $8 \mathrm{~h}$ after Rp. 5 administration \\
\hline \multicolumn{5}{|c|}{ Days 3-5 } \\
\hline \multirow{2}{*}{ Rp. 1} & Saline & $500 \mathrm{~mL}$ & & \\
\hline & SHC & $20 \mathrm{~mL}$ & $4 \mathrm{~h}$ & \\
\hline \multirow{2}{*}{ Rp. 2} & Saline & $100 \mathrm{~mL}$ & & \\
\hline & Dexamethasone & $9.9 \mathrm{mg}$ & $15 \mathrm{~min}$ & \\
\hline \multirow{2}{*}{ Rp. 3} & Saline & $50 \mathrm{~mL}$ & & \\
\hline & Mesna & $400 \mathrm{~mL} / \mathrm{m}^{2}$ & $15 \mathrm{~min}$ & \\
\hline \multirow{2}{*}{ Rp. 4} & Saline & $500 \mathrm{~mL}$ & & \\
\hline & Ifosfamide & $2 \mathrm{~g} / \mathrm{m}^{2}$ & $4 \mathrm{~h}$ & \\
\hline \multirow{2}{*}{ Rp. 5} & Saline & $500 \mathrm{~mL}$ & & \\
\hline & SHC & $20 \mathrm{~mL}$ & $4 \mathrm{~h}$ & \\
\hline \multirow{2}{*}{ Rp. 6} & Saline & $50 \mathrm{~mL}$ & & \\
\hline & Mesna & $400 \mathrm{ml} / \mathrm{m}^{2}$ & $15 \mathrm{~min}$ & $4 \mathrm{~h}$ after Rp. 4 administration \\
\hline \multirow{2}{*}{ Rp. 7} & Saline & $500 \mathrm{~mL}$ & & \\
\hline & SHC & $20 \mathrm{~mL}$ & $4 \mathrm{~h}$ & \\
\hline \multirow{2}{*}{ Rp. 8} & Saline & $50 \mathrm{~mL}$ & & \\
\hline & Mesna & $400 \mathrm{~mL} / \mathrm{m}^{2}$ & $15 \mathrm{~min}$ & $8 \mathrm{~h}$ after Rp. 4 administration \\
\hline
\end{tabular}

Abbreviations: Rp: recipe; SHC: sodium hydrogen carbonate, 8.4\%; PH: palonosetron hydrochloride; h: hour; min: minute; AI: doxorubicin-ifosfamide.

approved docetaxel dose in Japan is $75 \mathrm{mg} / \mathrm{m}^{2}$; the dose administered to our patient was $75 \mathrm{mg} / \mathrm{m}^{2}$ every 3 weeks.

Since effective adjuvant chemotherapy after curative surgery has not been reported, it was not administered, and the tumor in the left lung recurred 4 months after surgery. Selection of the subsequent chemotherapy drug was challenging. Although tumor regression was slow during the second half of AI therapy, regression was observed; given the lack of effective chemotherapy regimens for this situation, ifosfamide monotherapy was administered. The first course was completed smoothly and the patient was scheduled for discharge; however, her condition deteriorated suddenly, and she died soon thereafter. We believe that a cardiac or other important vessel ruptured during tumor regression; however, we were unable to confirm this hypothesis because an autopsy was not conducted.

Mitus et al. reported that AI therapy was useful for treating breast phyllodes tumors; 1 patient in their study achieved a complete response, and 2 patients achieved a partial response [10]. A complete response was not obtained in our case. 


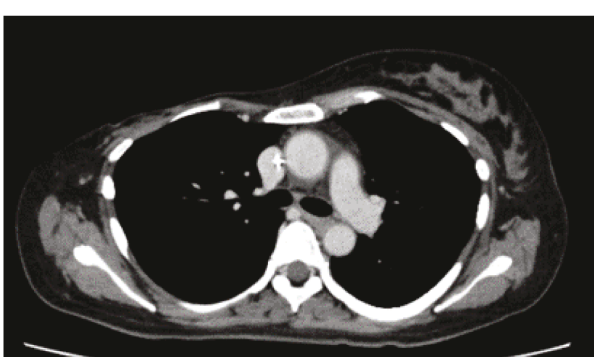

(a)

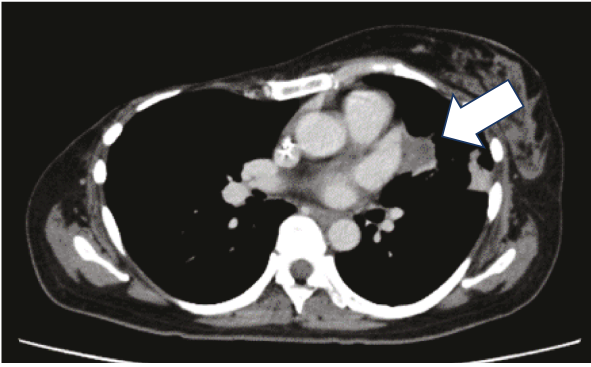

(b)

FIGURE 3: Computed tomography scan acquired after doxorubicin-ifosfamide (AI) chemotherapy showing (a) complete regression of the right lung mass and (b) partial regression of the left lung mass to $2 \mathrm{~cm}$ (arrow) and an absence of pleural effusion.

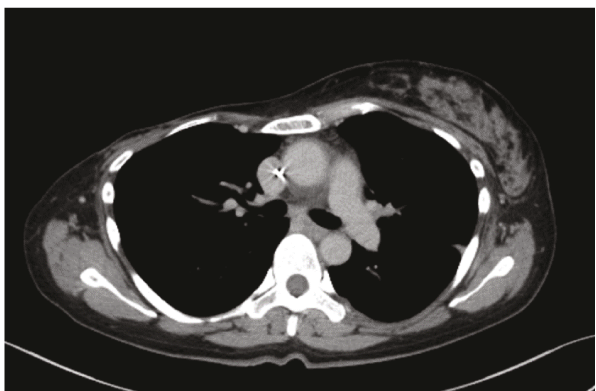

(a)

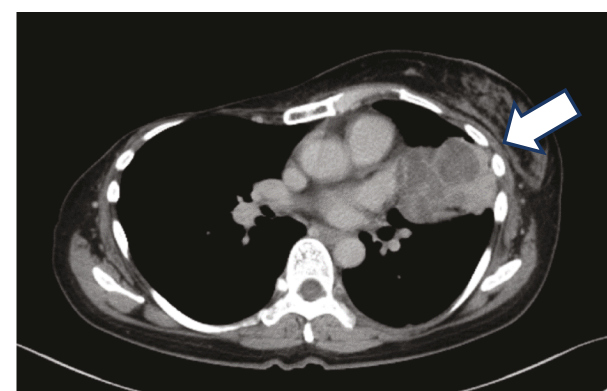

(b)

FIGURE 4: Computed tomography scan acquired after docetaxel chemotherapy showing (a) a lack of reappearance of the right lung mass and (b) an increase in the size of the left lung mass to $5.5 \mathrm{~cm}$ (arrow).

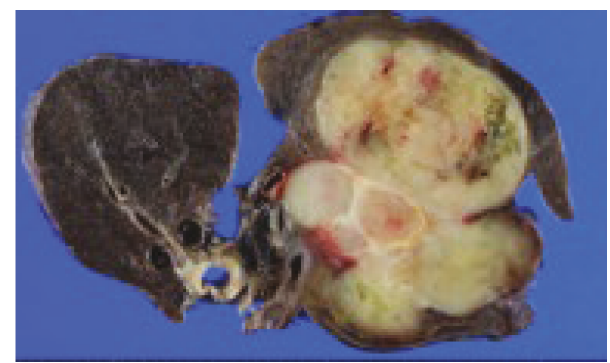

Figure 5: Pathological examination after lung surgery showing a $9 \mathrm{~cm}$ mass in the left lung reaching just under and partially adjacent to the pleura. There was no direct infiltration of the upper or the lower pulmonary vein or the pericardium.

Other possible treatments for a better prognosis included radiation therapy or the administration of another chemotherapy regimen such as a combination of docetaxel and gemcitabine. A dose of $10 \mathrm{~g} / \mathrm{m}^{2}$ of ifosfamide as a third therapy rather than $8 \mathrm{~g} / \mathrm{m}^{2}$ in each cycle may also be considered. Furthermore, it is arguable whether the option of surgery is appropriate when the disease has progressed. Moreover, AI therapy has been successful, but further treatment is still controversial.

Given the low frequency with which malignant breast phyllodes tumors occur, distant metastasis, large-scale clinical trials are not feasible. Hence, case reports represent an

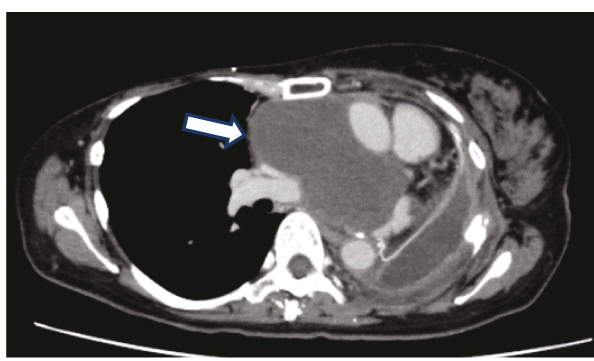

(a)

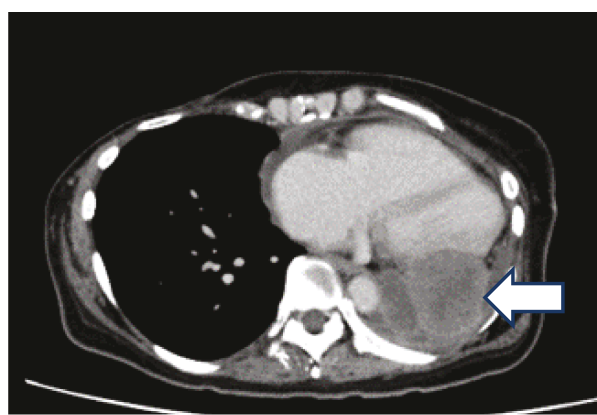

(b)

Figure 6: Computed tomography scan acquired 4 months after lung surgery showing (a) a $10 \mathrm{~cm}$ mass in the mediastinum (arrow) and (b) a $6 \mathrm{~cm}$ mass in the left thoracic cavity (arrow). 
important means by which to identify effective treatments. Although AI therapy was not curative in our case, it resulted in prominent tumor regression; therefore, this treatment strategy may be considered for use in other cases.

\section{Conclusion}

AI therapy is useful for treating recurrent malignant breast phyllodes tumors.

\section{Consent}

Informed consent for publication of this case report and any accompanying images was obtained using the opt-out system.

\section{Conflicts of Interest}

The authors declare that there are no conflicts of interest regarding the publication of this article.

\section{References}

[1] E. Y. Tan, T. P. Hoon, W. S. Yong et al., "Recurrent phyllodes tumours of the breast: pathological features and clinical implications," ANZ Journal of Surgery, vol. 76, no. 6, pp. 476-480, 2006.

[2] C. Confavreux, A. Lurkin, N. Mitton et al., "Sarcomas and malignant phyllodes tumours of the breast - a retrospective study," European Journal of Cancer, vol. 42, no. 16, pp. 2715-2721, 2006.

[3] P. Casali, U. Pastorino, A. Azzarelli et al., "Perspectives on anthracyclines plus ifosfamide in advanced soft tissue sarcomas," Cancer Chemotherapy and Pharmacology, vol. 31, Supplement 2, pp. S228-S232, 1993.

[4] S. Frustaci, F. Gherlinzoni, A. de Paoli et al., "Adjuvant chemotherapy for adult soft tissue sarcomas of the extremities and girdles: results of the Italian randomized cooperative trial," Journal of Clinical Oncology, vol. 19, no. 5, pp. 1238-1247, 2001.

[5] A. Le Cesne, I. Judson, D. Crowther et al., "Randomized phase III study comparing conventional-dose doxorubicin plus ifosfamide versus high-dose doxorubicin plus ifosfamide plus recombinant human granulocyte-macrophage colonystimulating factor in advanced soft tissue sarcomas: a trial of the European Organization for Research and Treatment of Cancer/Soft Tissue and Bone Sarcoma Group," Journal of Clinical Oncology, vol. 18, no. 14, pp. 2676-2684, 2000.

[6] S. Leyvraz, M. Bacchi, T. Cerny et al., "Phase I multicenter study of combined high-dose ifosfamide and doxorubicin in the treatment of advanced sarcomas," Annals of Oncology, vol. 9, no. 8, pp. 877-884, 1998.

[7] H. J. Weh, M. Zügel, D. Wingberg et al., "Chemotherapy of metastatic soft tissue sarcoma with a combination of adriamycin and DTIC or adriamycin and ifosfamide," Oncology Research and Treatment, vol. 13, no. 6, pp. 448-452, 1990.

[8] S. Leyvraz, R. Herrmann, L. Guillou et al., "Treatment of advanced soft-tissue sarcomas using a combined strategy of high-dose ifosfamide, high-dose doxorubicin and salvage therapies," British Journal of Cancer, vol. 95, no. 10, pp. 13421347, 2006.
[9] W. J. Köstler, T. Brodowicz, Y. Attems et al., "Docetaxel as rescue medication in anthracycline- and ifosfamide-resistant locally advanced or metastatic soft tissue sarcoma: results of a phase II trial," Annals of Oncology, vol. 12, no. 9, pp. 12811288, 2001.

[10] J. W. Mitus, P. Blecharz, T. Walasek, M. Reinfuss, J. Jakubowicz, and J. Kulpa, "Treatment of patients with distant metastases from phyllodes tumor of the breast," World Journal of Surgery, vol. 40, no. 2, pp. 323-328, 2016. 


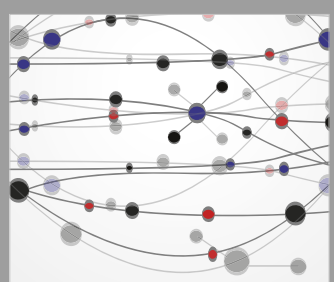

The Scientific World Journal
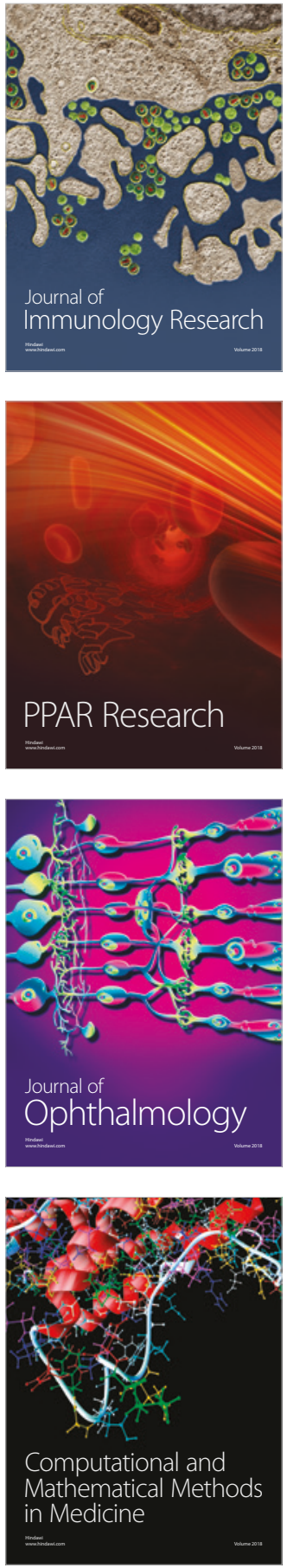

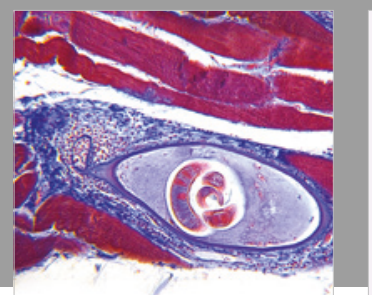

Gastroenterology Research and Practice

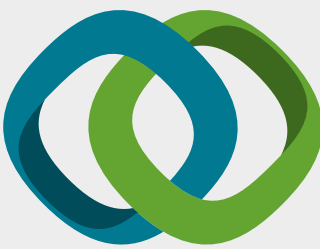

\section{Hindawi}

Submit your manuscripts at

www.hindawi.com
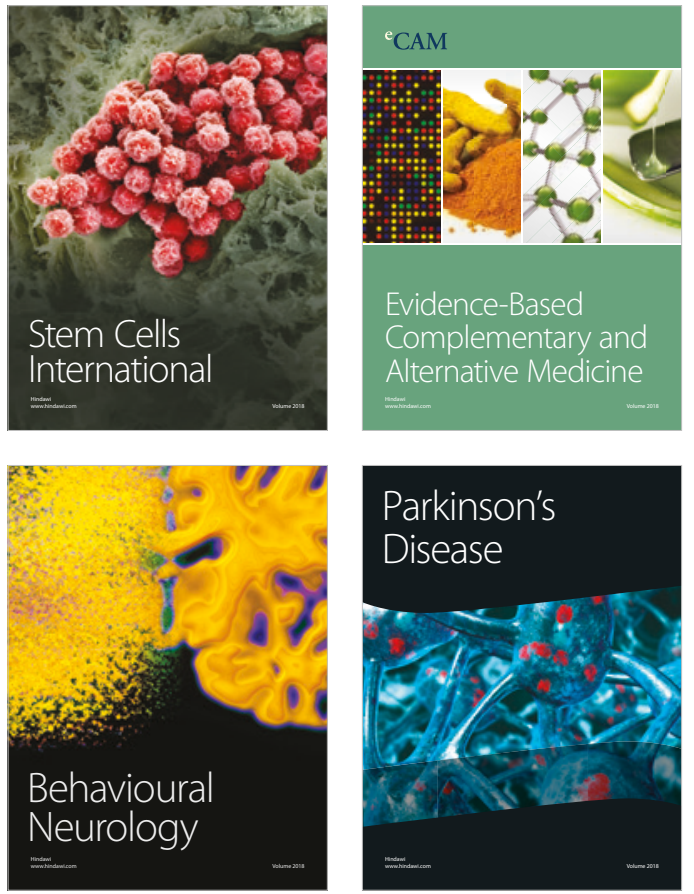

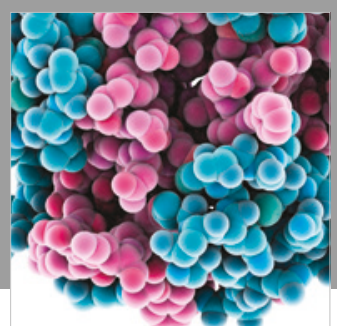

ournal of

Diabetes Research

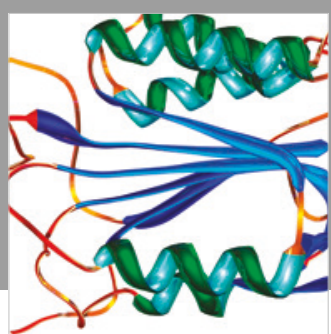

Disease Markers
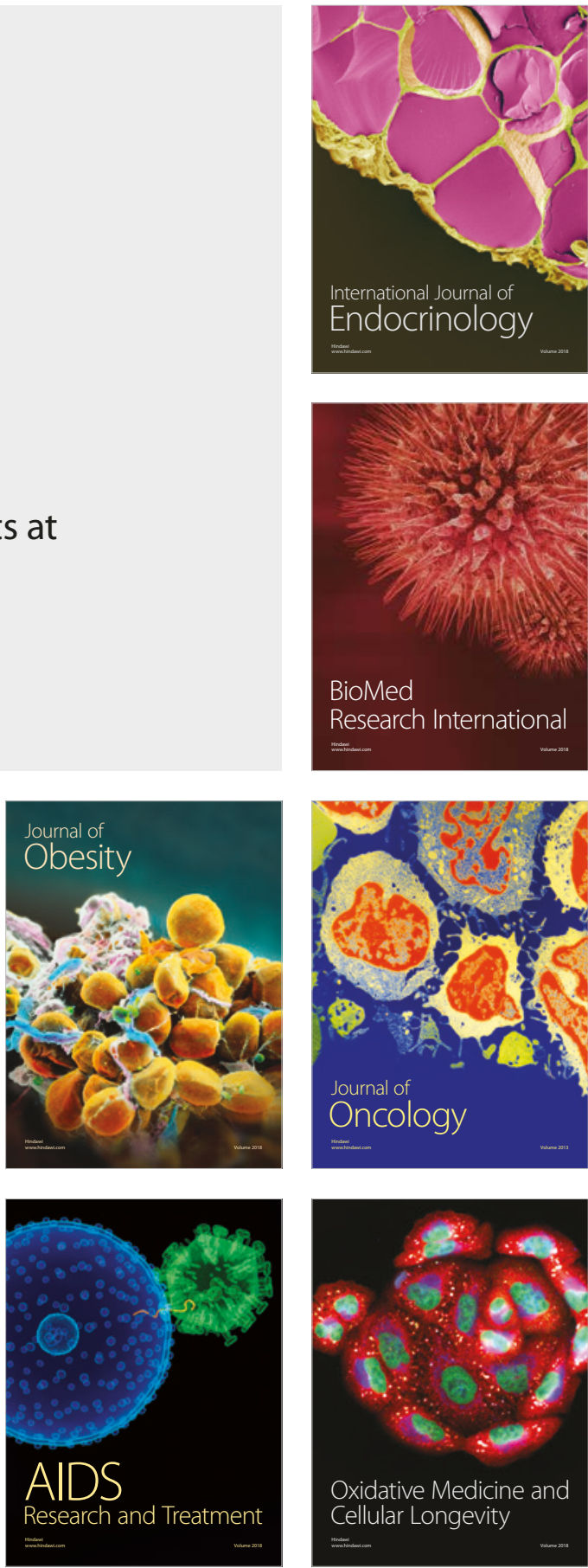